\title{
Mineração
}

\section{Flotação direta de minério de ferro com oleato de sódio}

\author{
(Iron ore direct flotation with sodium oleate)
}

\section{Resumo}

O objetivo desse trabalho foi estudar a possibilidade de concentração de minério de ferro por flotação direta, usando oleato de sódio como coletor dos minerais de ferro e o metassilicato de sódio como depressor da ganga silicosa. Após a caracterização das amostras minerais e do minério, foram feitos estudos fundamentais, que englobaram a determinação do potencial zeta dos minerais hematita e quartzo, cujos valores de PIE ocorreram em pH 7,5 e 1,8, respectivamente. Os ensaios de microflotação, em tubo de Hallimond modificado, determinaram as condições de maior flotabilidade da hematita, $50 \mathrm{mg} / \mathrm{L}$ de oleato de sódio em $\mathrm{pH}$ 7, e do quartzo, $70 \mathrm{mg} / \mathrm{L}$ de oleato de sódio em pH 9. Os ensaios de microflotação, ainda mostraram que o metassilicato de sódio foi mais efetivo na depressão da hematita que na depressão do quartzo. Os ensaios de flotação em bancada confirmaram esse comportamento, ou seja, o metassilicato de sódio não propicia separação seletiva entre a hematita e o quartzo durante a flotação. O melhor concentrado fornecido pela flotação direta da amostra de minério de ferro, cujos teores de Fe e $\mathrm{SiO}_{2}$ eram, respectivamente, de 35,34 e 48,02\%, foi obtido usando-se dosagens de $600 \mathrm{~g} / \mathrm{t}$ de metassilicato de sódio e $1200 \mathrm{~g} / \mathrm{t}$ de oleato de sódio: recuperação metalúrgica de $\mathrm{Fe}$ de $88 \%$, teor de $\mathrm{Fe}$ de $58,1 \%$ e teor de $\mathrm{SiO}_{2}$ de $14,4 \%$.

Palavras - chave: Flotação direta, minério de ferro, oleato de sódio, metassilicato de sódio.

\section{Abstract}

The goal of this paper was to study the possibility of concentrating iron ore by direct flotation with sodium oleate as a collector of iron minerals and a water glass as a depressant of the siliceous gangue. Following characterization studies of minerals and iron ore samples, fundamental studies with mineral samples of hematite and quartz were performed: zeta potential determinations and microflotation tests in a modified Hallimond tube. The isoelectric points of hematite and quartz were determined at $p H=7.5$ and 1.8 , respectively. The highest hematite floatability was achieved at $50 \mathrm{mg} / \mathrm{L}$ sodium oleate dosage, at $\mathrm{pH}=7$, and of quartz at $70 \mathrm{mg} / \mathrm{L}$ sodium oleate dosage, at $\mathrm{pH}=9$. It was observed from microflotation tests that the water glass was more effective in depressing hematite than quartz. The batch flotation tests confirmed the results of the microflotation tests. It means that the water glass is not conducive to selective flotation separation between hematite and quartz. The best results obtained with the iron ore sample $\left(33.34 \% \mathrm{Fe}\right.$ and $48.02 \% \mathrm{SiO}_{2}$ contents) were: an Fe metallurgical recovery of $88 \%$, and $\mathrm{Fe}$ and $\mathrm{SiO}$, concentrate grades of $58.08 \%$ and $14.4 \%$, respectively, achieved with $600 \mathrm{~g} / \mathrm{t}$ water glass and $1200 \mathrm{~g} / \mathrm{t}$ sodium oleate.

Keywords: Direct flotation, iron ore, sodium oleate, water glass. 


\section{Introdução}

A exaustão de depósitos de minérios de ferro de altos teores torna necessária a utilização de métodos de concentração para obtenção de produtos que atendam às especificações da indústria siderúrgica, principal consumidora de concentrados de minério de ferro, cujos teores mínimos de Fe são da ordem de 64\%. Dependendo da distribuição granulométrica e do teor do minério, industrialmente são utilizados, com sucesso, três métodos de concentração, que estão citados na ordem crescente de complexidade e custos: concentração gravítica, concentração magnética e flotação reversa.

Segundo Numela e Iwasaki (1986), a flotação de minério de ferro é utilizada com as seguintes finalidades:

i) Concentração de minérios de ferro não magnéticos pela flotação da sílica (flotação reversa) ou da hematita (flotação direta).

ii) Remoção da sílica abaixo de $0,044 \mathrm{~mm}$ dos concentrados magnéticos.

iii) Preparação de superconcentrados para redução direta.

iv) Redução do nível de impurezas, além da sílica, como o sódio, o fósforo e o enxofre.

Houot (1982) descreve as possíveis rotas de flotação direta de minérios de ferro e cita o uso de oleato como coletor dos minerais de ferro. O oleato de sódio adsorve-se quimicamente na superfície dos oximinerais, que são coletados na espuma de flotação. Essa adsorção química se dá pela formação de ligações químicas covalentes entre a superfície da hematita e o ânion coletor. Peck et al. (1966), citados por Quast (1999), confirmaram a formação dessas ligações com estudos de espectroscopia no infravermelho, mostrando o aparecimento de um novo composto químico, o oleato férrico, caracterizado pelo aparecimento de uma banda de absorção na região de $1565 \mathrm{~cm}^{-1}$. Segundo Quast (1999), a máxima adsorção de ácido oleico sobre hematita ocorre no $\mathrm{pH}$ coincidente com o PIE (ponto isoelétrico) do mineral, sen- do que, em pH's mais alcalinos, predomina a competição entre os íons oleato e hidroxil pelos sítios ativos presentes na superfície da hematita. Como depressor da ganga silicatada, Rao (2004) cita o silicato de sódio. As espécies altamente hidrofílicas formadas pela dissolução do silicato de sódio em água são responsáveis pelo aumento da hidrofilicidade do mineral e, conseqüentemente, pela depressão da ganga silicatada.

Vieira (1994) estudou a viabilidade técnica de concentração de um itabirito com $46 \%$ de Fe, usando flotação direta em escala de bancada com oleato de sódio como coletor dos óxidos de ferro e silicato de sódio como depressor da ganga silicatada. As variáveis estudadas foram: $\mathrm{pH}$ de flotação, dosagem de coletor e dosagem de depressor. $\mathrm{O}$ pH de maior recuperação foi 7 e a dosagem de oleato de sódio foi de $30 \mathrm{~g} / \mathrm{t}$, na ausência de silicato de sódio. O concentrado obtido nessas condições apresentou os seguintes teores: $65,5 \%$ de $\mathrm{Fe}, 4,7 \%$ de $\mathrm{SiO}_{2}$ e recuperação metalúrgica de 78,46\%.

Nesse trabalho, são apresentados os resultados de estudos de flotação direta de minério de ferro. Em uma primeira fase, foram efetuados estudos fundamentais, que consistiram do levantamento das curvas de potencial zeta da hematita e do quartzo, ambos condicionados com água destilada em valores de $\mathrm{pH}$ variando de 2 a 12, de ensaios de microflotação dos minerais puros hematita e quartzo, condicionados com o coletor oleato de sódio e com o depressor metassilicato de sódio, seguido de condicionamento com o coletor oleato de sódio e, finalmente, ensaios em escala de bancada com uma amostra de minério considerada de "baixo teor de ferro".

\section{Materiais e métodos}

A caracterização das amostras de minerais puras (hematita e quartzo) consistiu de análise química, efetuada por espectrometria de emissão atômica com fonte plasma (Spectro/Modelo - Ciros CCD) do DEGEO/UFOP e por método gravimétrico para determinação do teor de $\mathrm{SiO}_{2}$.
A determinação da distribuição granulométrica do minério foi efetuada por peneiramento a úmido. Posteriormente, após agrupamento adequado das frações granulométricas, efetuaram-se análise mineralógica por difratometria de raios X, usando o difratômetro RIGAKU/ série D/Max-B do DEGEO/UFOP, e análise química por fluorescência de raios $\mathrm{X}$, usando o espectrômetroRIGAKU/modelo 3550 da Vale.

A determinação das curvas de potencial zeta das amostras minerais puras, condicionadas em água destilada, foi efetuada em Zetasizer Nano Z Malvern.

Foram usados ácido oleico saponificado com hidróxido de sódio (solução a $1 \%$ p/v) e solução a $5 \%$ p/v de metassilicato de sódio, ambos da CromolineQuímica Fina. Os ajustes dos valores de $\mathrm{pH}$ foram efetuados por soluções de hidróxido de sódio e ácido clorídrico em concentrações adequadas ao $\mathrm{pH}$ do ensaio.

Os ensaios de microflotação foram efetuados em tubo de Hallimond modificado usando 1 grama de mineral puro (faixa granulométrica entre 106 e $45 \mu \mathrm{m}$ ) e vazão de $60 \mathrm{~mL} / \mathrm{min}$ de nitrogênio industrial. Os tempos de condicionamento dos minerais com cada reagente foram de 4 minutos, para a hematita com oleato de sódio, e de 6 minutos com metassilicato de sódio. Para o quartzo, o tempo foi de 6 minutos de condicionamento com oleato de sódio e de 6 minutos com metassilicato de sódio. As variáveis estudadas foram o $\mathrm{pH}$ e a dosagem de oleato de sódio. Após a determinação das melhores condições de flotabilidade dos minerais hematita e quartzo ( $\mathrm{pH}$ e dosagem de coletor), esses valores foram fixados e procedeu-se o estudo da dosagem do depressor metassilicato de sódio.

A metodologia para determinação das curvas de potencial zeta, preparação dos reagentes e ensaios de microflotação foi descrita em detalhes por Lopes (2009).

Para os ensaios de flotação em escala de bancada, fixaram-se o valor de pH em 7, determinado, previamente, nos ensaios de microflotação, e a rotação da 
Gilmara Mendonça Lopes et al.

célula de flotação em 1200 RPM. Os ensaios foram planejados e executados através das técnicas de planejamento fatorial de experimentos, com réplica. Foram estudadas três variáveis em dois níveis: dosagem de metassilicato de sódio (A), dosagem de oleato de sódio (B) e porcentagem de sólidos $(\mathrm{C})$. As variáveis respostas analisadas foram recuperação metalúrgica de $\mathrm{Fe}(\mathrm{X})$, teores de $\mathrm{Fe}(\mathrm{Y})$ e $\mathrm{SiO}_{2}(\mathrm{Z})$ no concentrado. Na Tabela 1 , estão apresentadas as variáveis estudadas com suas respectivas codificações e níveis testados.

\section{Resultados e Discussão}

\subsection{Caracterização das amostras minerais e do minério}

$\mathrm{Na}$ Tabela 2, estão apresentadas as composições químicas das amostras minerais puras, hematita e quartzo. A amostra de hematita apresenta, como principais impurezas, $\mathrm{SiO}_{2}(0,73 \%)$ e $\mathrm{Al}_{2} \mathrm{O}_{3}$ $(0,49 \%)$ e goethita (PPC de $0,31 \%)$. No caso da amostra de quartzo, observa-se que as maiores impurezas são $\mathrm{Al}_{2} \mathrm{O}_{3}$ $(0,22 \%)$ e $\mathrm{CaO}(0,20 \%)$.

Na Tabela 3, está apresentada a composição mineralógica por faixa granulométrica da amostra de minério de ferro, usada nos ensaios de flotação em escala de bancada. Como pode ser observado, foram identificados os minerais goethita, caulinita e muscovita somente na fração granulométrica abaixo de $38 \mu \mathrm{m}$.

A composição granuloquímica do minério de ferro está apresentada na Tabela 4. Observa-se que os teores globais de $\mathrm{Fe}$ e $\mathrm{SiO}_{2}$ do minério são de 35,34 e 48, $02 \%$, respectivamente. Nota-se, ainda, que os maiores teores de Fe são observados nas frações mais finas do minério e um comportamento inverso é observado no que diz respeito aos teores de $\mathrm{SiO}_{2}$. A maior perda por calcinação (PPC) foi observada na fração abaixo de $38 \mu \mathrm{m}$ e está relacionada à presença dos filossilicatos identificados nessa faixa (caulinta, goethita e muscovita).

Tabela 1 - Planejamento fatorial de experimentos $2^{3}$ para os ensaios de flotação em bancada.

\begin{tabular}{c|c|c|c}
\hline \multirow{2}{*}{ Reagente } & \multirow{2}{*}{ Codificação } & \multicolumn{2}{|c}{ Nível } \\
\cline { 3 - 4 } & & - & + \\
\hline Metassilicato de sódio (g/t) & (A) & 600 & 1200 \\
\hline Oleato de sódio (g/t) & (B) & 600 & 1200 \\
\hline$\%$ sólidos & (C) & 30 & 60 \\
\hline
\end{tabular}

Tabela 2 - Composição química das amostras minerais.

\begin{tabular}{|c|c|c|c|}
\hline \multicolumn{2}{|c|}{ Hematita } & \multicolumn{2}{|c|}{ Quartzo } \\
\hline Óxido/elemento & Teor $(\%)$ & Óxido & Teor $(\%)$ \\
\hline Ferro total & 68,68 & $\mathrm{SiO}_{2}$ & 99,00 \\
\hline $\mathrm{FeO}$ & 0,22 & $\mathrm{Al}_{2} \mathrm{O}_{3}$ & 0,2218 \\
\hline $\mathrm{SiO}_{2}$ & 0,73 & $\mathrm{CaO}$ & 0,2013 \\
\hline $\mathrm{Al}_{2} \mathrm{O}_{3}$ & 0,4957 & $\mathrm{Fe}_{2} \mathrm{O}_{3}$ & 0,0494 \\
\hline $\mathrm{P}_{2} \mathrm{O}_{5}$ & 0,0366 & $\mathrm{~K}_{2} \mathrm{O}$ & 0,0377 \\
\hline $\mathrm{MnO}$ & 0,1369 & $\mathrm{MgO}$ & 0,0348 \\
\hline $\mathrm{CaO}$ & 0,0464 & $\mathrm{MnO}$ & - \\
\hline $\mathrm{TiO}_{2}$ & 0,0484 & $\mathrm{Na}_{2} \mathrm{O}$ & 0,0249 \\
\hline PPC & 0,31 & $\mathrm{TiO}_{2}$ & 0,0035 \\
\hline
\end{tabular}

\subsection{Estudos fundamentais}

Na Figura 1, estão apresentadas as curvas de potencial zeta da hematita e do quartzo, condicionados com água destilada. Como pode ser observado, os valores de potencial zeta do quartzo são bem mais negativos do que os valores de potencial zeta da hematita. O ponto isoelétrico (PIE) do quartzo ocorre em $\mathrm{pH}$ 1,8 (concordante com o valor da literatura) e o da hematita, em pH 7,5. A diferença observada entre os valores obtidos, experimentalmente, e os da literatura encontrados por Fuerstenau (1976), para a hematita $(5,6$ e 6,7$)$ é atribuída às diferenças mineralógicas entre as amostras analisadas, equipamento e à aquelas das impurezas.
Nas Figuras 2 e 3, estão apresentadas as curvas de flotabilidade da hematita e do quartzo em função da dosagem de oleato de sódio e do $\mathrm{pH}$. A maior flotabilidade da hematita foi observada em pH 7 e usando $50 \mathrm{mg} / \mathrm{L}$ de oleato de sódio. Vieira (1994) também cita o $\mathrm{pH} 7$ como sendo o de maior flotabilidade em ensaios de flotação em bancada com uma amostra de itabirito. Em pH's acima de 9, os íons oleato e hidroxila presentes na solução concorrem entre si pelos sítios superficiais da hematita, provocando uma queda brusca na flotabilidade, conforme pode ser observado na Figura 2.

No caso do quartzo, a dosagem de oleato de sódio, que conduziu à maior flotabilidade (95\%), foi de $70 \mathrm{mg} / \mathrm{L} \mathrm{em} \mathrm{pH} 9$. 
Flotação direta de minério de ferro com oleato de sódio

Tabela 3 - Composição mineralógica do minério de ferro por faixa granulométrica.

\begin{tabular}{|c|c|c|c|c|c|c|}
\hline \multirow{3}{*}{$\begin{array}{c}\text { Faixa } \\
\text { granul. } \\
\mu \mathrm{m}\end{array}$} & \multirow{3}{*}{$\begin{array}{c}\% \\
\text { Simples }\end{array}$} & \multicolumn{5}{|c|}{ Minerais identificados } \\
\hline & & Hematita & Goethita & Quartzo & Caulinita & Moscovita \\
\hline & & $\left(\mathrm{Fe}_{2} \mathrm{O}_{3}\right)$ & (FeOOH) & $\left(\mathrm{SiO}_{2}\right)$ & $\left(\mathrm{Al}_{2} \mathrm{Si}_{2} \mathrm{O}_{5}(\mathrm{OH})_{4}\right.$ & $\left(\mathrm{KAl}_{2}\left(\mathrm{Si}_{3} \mathrm{Al}\right) \mathrm{O}_{10}(\mathrm{OH}, \mathrm{F})_{2}\right)$ \\
\hline 104 & 34,9 & $x$ & - & $x$ & - & - \\
\hline-30 & 27,9 & $x$ & - & $x$ & - & - \\
\hline-36 & 20,9 & $x$ & - & $x$ & - & - \\
\hline-38 & 16,3 & $x$ & $x$ & $x$ & $x$ & $x$ \\
\hline
\end{tabular}

Tabela 4 - Análise granuloquímica da amostra de minério de ferro.

\begin{tabular}{|c|c|c|c|c|c|c|c|c|c|c|c|c|}
\hline \multirow{2}{*}{$\begin{array}{c}\text { Tamanho } \\
(\mu \mathrm{m})\end{array}$} & \multirow{2}{*}{$\% \mathrm{~S}$} & \multicolumn{9}{|c|}{ Teores (\%) } & \multicolumn{2}{|c|}{ Distribuição (\%) } \\
\hline & & $\mathrm{Fe}$ & $\mathrm{SiO}_{2}$ & $\mathbf{P}$ & $\mathrm{Al}_{2} \mathrm{O}_{3}$ & Mn & $\mathrm{TiO}_{2}$ & $\mathrm{CaO}$ & MgO & PPC & $\mathrm{Fe}$ & $\mathrm{SiO}_{2}$ \\
\hline 105 & 34,9 & 29,78 & 57,3 & 0,01 & 0,24 & 0,02 & 0,029 & 0,007 & 0,036 & 0,22 & 30,0 & 40,78 \\
\hline-31 & 27,9 & 32,12 & 53,8 & 0,01 & 0,33 & 0,02 & 0,032 & 0,012 & 0,028 & 0,31 & 25,9 & 30,61 \\
\hline-36 & 20,9 & 37,98 & 44,5 & 0,02 & 0,74 & 0,07 & 0,042 & 0,025 & 0,111 & 0,53 & 22,9 & 18,97 \\
\hline-38 & 16,3 & 45,19 & 29,04 & 0,04 & 3,66 & 0,10 & 0,053 & 0,075 & 0,255 & 1,92 & 21,3 & 9,65 \\
\hline \multicolumn{2}{|c|}{ Total recalculado } & 35,34 & 48,02 & 0,02 & 0,95 & 0,04 & 0,040 & 0,02 & 0,080 & 0,61 & 100,0 & 100,0 \\
\hline
\end{tabular}

Comparando-se as Figuras 2 e 3, observa-se que há maior afinidade entre o íon oleato e a superfície da hematita, evidenciada pela alta flotabilidade desse mineral na presença de menores concentrações de oleato. Essa maior flotabilidade da hematita em relação ao quartzo é da ordem de $40 \%$ quando são usados $50 \mathrm{mg} / \mathrm{L}$ de oleato de sódio em pH 7, ou seja, não é possível a separação seletiva entre os dois minerais somente com o uso de oleato de sódio, fazendo-se necessário o emprego de depressor.

Pela análise das curvas de potencial zeta apresentadas na Figura 1 e das curvas de flotabilidade da hematita e quartzo apresentadas nas Figuras 2 e 3, observa-se que houve adsorção do oleato sobre a superfície do quartzo em



Figura 1 - Potencial zeta da hematita e quartzo condicionados em água destilada. 
pH 9, evidenciada pela reversão do potencial zeta, primeira premissa para justificar a ocorrência de adsorção química. Em pH 7, a hematita apresenta carga superficial ligeiramente positiva, propiciando a atração eletrostática entre seus sítios e o íon oleato carregado negativamente. Peck et al. (1966), citados por Quast (1999), comprovaram que a adsorção do oleato sobre a superfície da hematita é química, atestada pelo aparecimento de uma banda de absorção no espectro infravermelho da hematita condicionada com oleato de sódio na região de $1565 \mathrm{~cm}^{-1}$ atribuída à formação do "composto químico" oleato férrico. Esse fato é comprovado pela reversão do potencial zeta da hematita em $\mathrm{pH}$ acima de 7, quando a superfície da hematita torna-se carregada negativamente devido à adsorção química do íon oleato.

Comparando-se as Figuras 4 e 5, verifica-se que o metassilicato de sódio foi mais efetivo na depressão da hematita: $0,7 \%$ de flotabilidade da hematita contra $16 \%$ de flotabilidade para o quartzo usando $20 \mathrm{~g} / \mathrm{L}$ de metassilicato de sódio em ambos os casos. Portanto o metassilicato de sódio não é um depressor seletivo no sistema hematita/quartzo quando o oleato de sódio é usado como coletor.

\subsection{Ensaios de flotação em escala de bancada}

Lopes (2009) construiu os algoritmos de Yates para analisar os resultados provenientes do primeiro planejamento de experimentos. As equações encontradas ilustram a influência das variáveis estudadas (dosagem de metassilicato de sódio - A, dosagem de oleato de sódio B e porcentagem de sólido - C) sobre as variáveis respostas analisadas (recuperação metalúrgica - $X$, teor de Fe no concentrado - $\mathrm{Y}$ e teor de $\mathrm{SiO}_{2}-\mathrm{Z}$ ) no concentrado. As equações são mostradas a seguir.

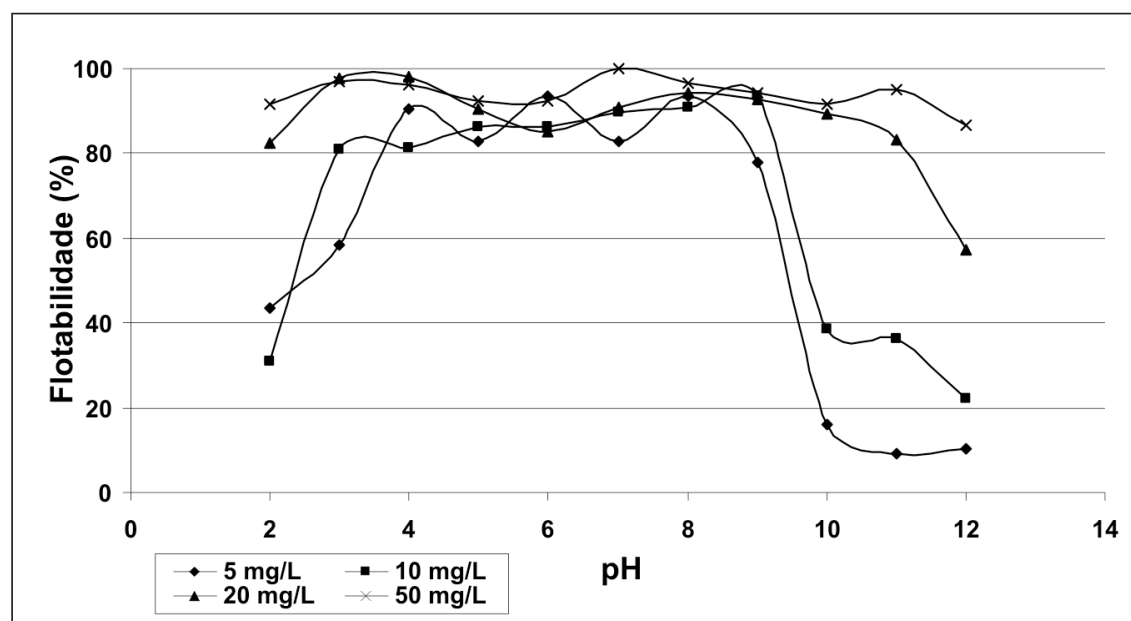

Figura 2 - Influência da dosagem de oleato de sódio sobre a flotabilidade da hematita em função do $\mathrm{pH}$.



Figura 3 - Relação entre a dosagem de oleato de sódio e a flotabilidade do quartzo em função do $\mathrm{pH}$.



Figura 4 - Efeito da adição de metassilicato de sódio sobre a flotabilidade da hematita em $\mathrm{pH} 7$ para dosagem de oleato de sódio de $50 \mathrm{mg} / \mathrm{L}$. 
Flotação direta de minério de ferro com oleato de sódio

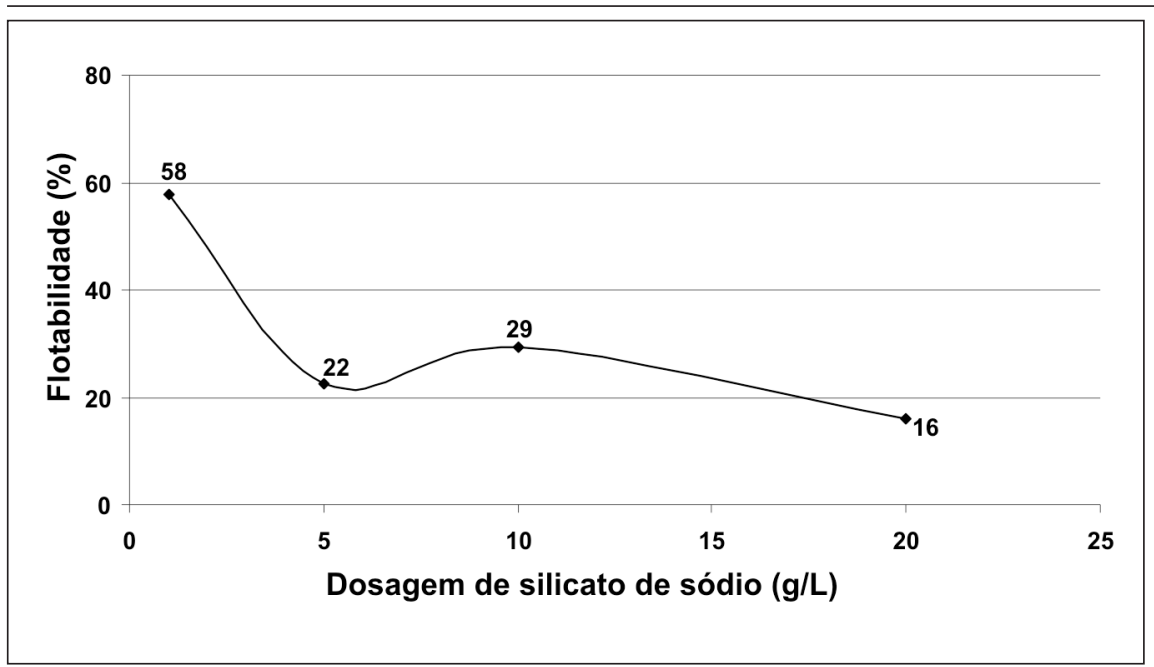

Figura 5 - Influência da adição de metassilicato de sódio sobre a flotabilidade do quartzo em pH 9 e dosagem de oleato de sódio de $70 \mathrm{mg} / \mathrm{L}$.

$\mathrm{X}=41,94+87,05 \mathrm{~A}-6,16 \mathrm{~B}+0,20 \mathrm{C}$

$\mathrm{Y}=23,58+52,42 \mathrm{~A}+0,81 \mathrm{~B}+2,99 \mathrm{AB}+2,01 \mathrm{AC}$

$\mathrm{Z}=15,22+22,43 \mathrm{~A}-4,21 \mathrm{AB}-2,94 \mathrm{AC}$

Observa-se que as três variáveis estudadas têm efeito sobre as três variáveis respostas de interesse. Após a análise gráfica efetuada por Lopes (2009), foram fixadas a fração de sólidos da polpa em $60 \%$ (C) e a dosagem de metassilicato de sódio em $600 \mathrm{~g} / \mathrm{t}$ (A). O segundo planejamento de experimentos foi executado variando-se apenas a dosagem de oleato de sódio, ilustrado na Figura 6.
Como pode ser observado na Figura 6, a maior recuperação metalúrgica de Fe foi de $88 \%$. Os teores de $\mathrm{Fe} \mathrm{e} \mathrm{SiO}_{2}$ no concentrado foram de, respectivamente, 58,08 e $14,4 \%$, porcentagens fornecidas pela flotação direta usando $600 \mathrm{~g} / \mathrm{t}$ de metassilicato de sódio, $1200 \mathrm{~g} / \mathrm{t}$ de oleato de sódio e polpa com $60 \%$ de sólidos. Esses valores são piores do que aqueles obtidos por Vieira (1994): recuperação metalúrgica de $\mathrm{Fe}$ de $78,46 \%$, teor de $\mathrm{Fe}$ de $65,5 \%$ e de $\mathrm{SiO}_{2}$ de $4,7 \%$ no concentrado. No entanto, há de salientar que o minério tratado por Vieira era bitolado e com teor de Fe cerca de $10 \%$ maior que o teor de Fe da amostra estudada nesse trabalho e que esses valores foram obtidos usando somente oleato de sódio $(30 \mathrm{~g} / \mathrm{t})$.

De uma maneira geral, pode-se afirmar que os elevados teores de $\mathrm{SiO}_{2}$ obtidos no concentrado da flotação direta da amostra de minério de ferro, usando metassilicato de sódio como "depressor" e oleato de sódio como coletor, estão perfeitamente coerentes com os resultados obtidos na microflotação das amostras minerais puras, ou seja, o metassili-

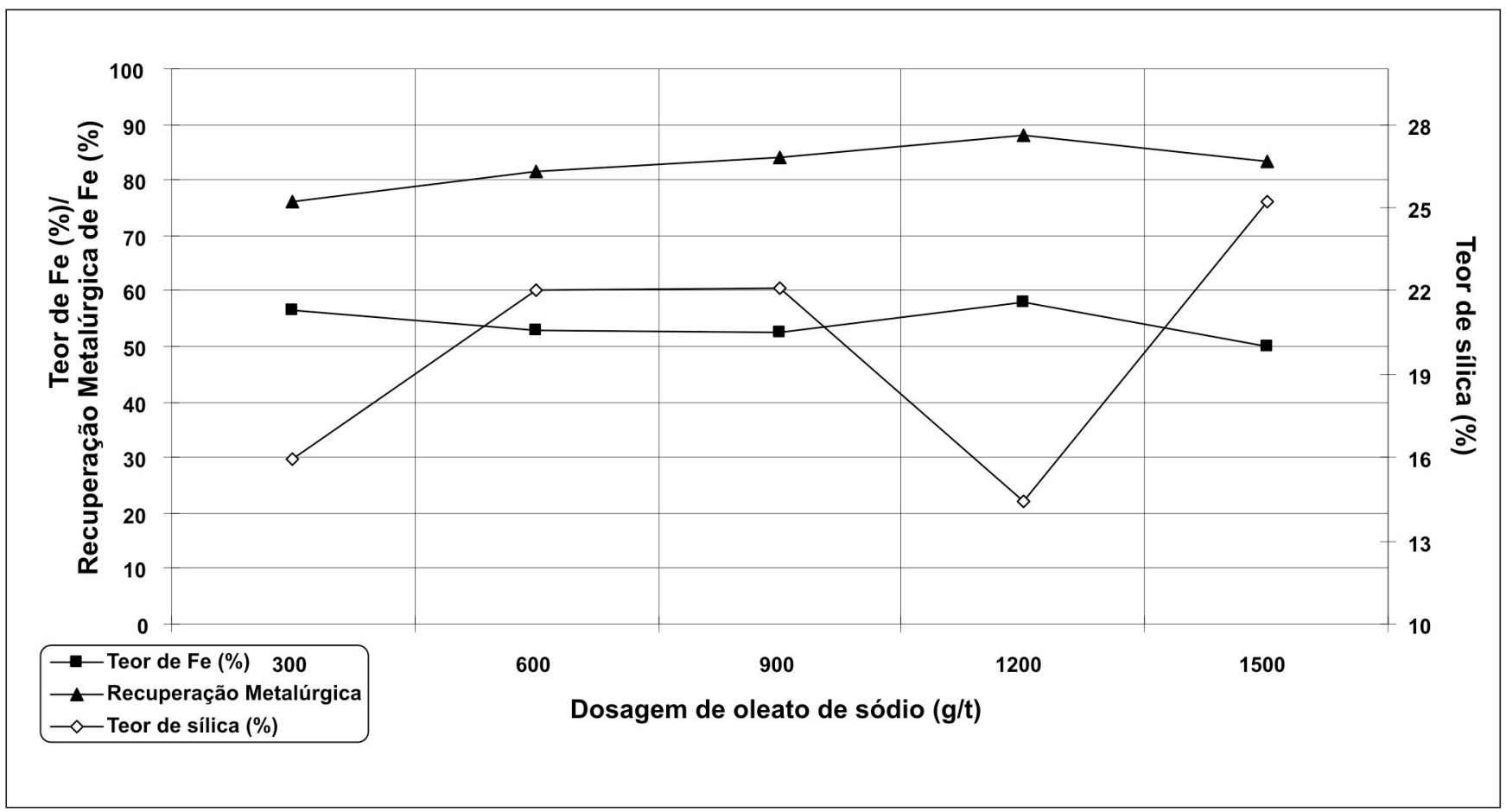

Figura 6 - Influência da dosagem de oleato de sódio sobre a recuperação metalúrgica de $\mathrm{Fe}$, teor de $\mathrm{Fe}$ e $\mathrm{SiO}_{2}$ no concentrado da flotação direta usando oleato de sódio como coletor, polpa com $60 \%$ de sólidos e $600 \mathrm{~g} / \mathrm{t}$ de metassilicato de sódio como depressor. 
cato mostrou maior afinidade pela hematita do que pelo quartzo (Figuras 4 e 5). Logo, a baixa seletividade alcançada na flotação direta de minério de ferro, usando metassilicato de sódio e oleato de sódio, não está relacionada com existência de lamas presentes nas amostras.

\section{Conclusões}

O ponto isoelétrico (PIE) da hematita ocorreu em $\mathrm{pH}$ 7,5 e o do quartzo, em $\mathrm{pH} 1,8$.

Os valores de $\mathrm{pH}$ de maior flotabilidade da hematita e do quartzo, usando oleato de sódio como coletor, foram, respectivamente, 7 e 9, determinados nos ensaios de microflotação.

Os ensaios de microflotação usando metassilicato de sódio como depressor mostraram que tanto quartzo quanto hematita foram deprimidos e que a depressão da hematita foi maior.

Os ensaios de flotação em bancada confirmaram os resultados obtidos nos ensaios de microflotação, ou seja, o metassilicato de sódio não propicia separação seletiva entre o quartzo e a hematita. Por essa razão, o melhor concentrado obtido continha teor de $\mathrm{Fe}$ de $58,1 \%$ e teor de $\mathrm{SiO}_{2}$ de $14,4 \%$, para uma recuperação metalúrgica de Fe de $88 \%$.

\section{Agradecimentos}

As autoras agradecem à Capes pela concessão da bolsa de mestrado e à Vale pelo financiamento do projeto.

\section{Referências bibliográficas}

FUERSTENAU, M.C. (Ed.). Flotation: A.M. Gaudin Memorial Volume. New York: American Institute of Mining, Metallurgical and Petroleum Engineers, 1976. 621p. v.1, p.148-196.

HOUOT, R. Beneficiation of iron ore by flotation-review of industrial and potential applications. International Journal of Mineral Processing, v.10, n.3, p. 183-204, 1983.

LOPES, G.M. Flotação direta de minério de ferro. Ouro Preto: Departamento de Engenharia de Minas, Universidade Federal de Ouro Preto, 2009. 175p. (Dissertação de Mestrado).

NUMELA, W., IWASAKI, I. Iron ore flotation. In: SOMASUNDARAN, P. Advances in mineral processing. Litttleton, Colorado: SME, 1986. 756p. cap. 18, p.308-342.

QUAST, K.B. Flotation of hematite using oleate as collectors. The AusIMM Proceedings, n.1, p. 7-13, 1999

RAO, S.R. Surface chemistry of froth flotation. New York: Kluwer Academic/Plenum Publishers, 2004. 744 p.

VIEIRA, A.M. Estudo da viabilidade técnica da concentração de um minério de ferro de baixo teor. Belo Horizonte: Escola de Engenharia, Universidade Federal de Minas Gerais, 1994. 174p. (Dissertação de Mestrado).

Artigo recebido em 24/03/2009 e aprovado em 14/04/2009.

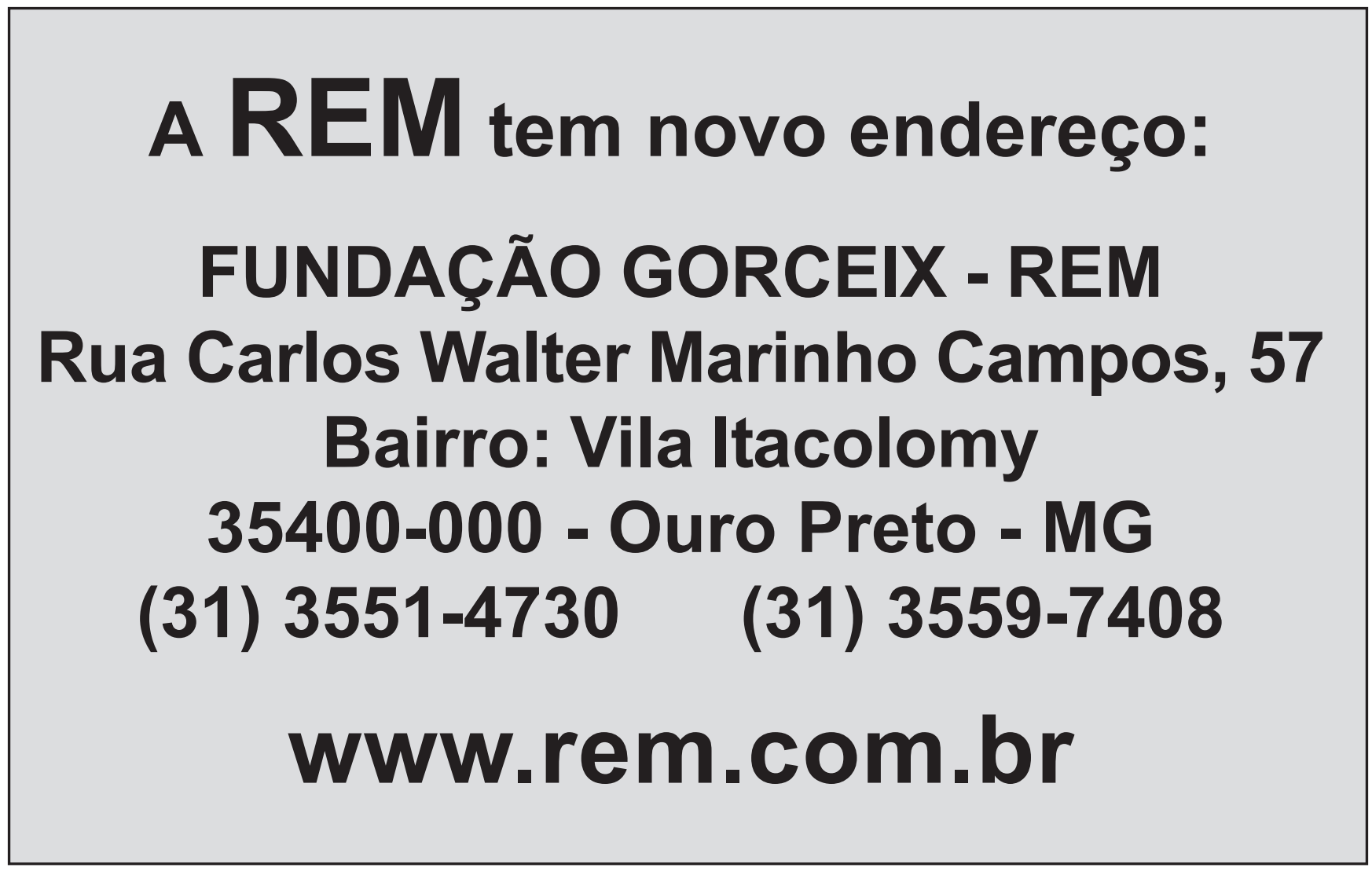

